\title{
PEMBUATAN HULL PERAHU IKAN CADIK FIBER GLASS SKALA KECIL BAGI MITRA KELOMPOK NELAYAN
}

\author{
Amir Marasabessy ${ }^{1}$, Iswadi Nur ${ }^{2}$, Rusdy Hatuwe ${ }^{3}$ \\ Teknik Perkapalan, Fakultas Teknik, Universitas Pembangunan Nasional “Veteran” Jakarta ${ }^{12} 3$ \\ Email:amir141161@gmail.com
}

\begin{abstract}
Event Service to the community for the partner group of fishermen village of Caringin District of Labuan Pandeglang in Banten Province aims to provide training and manufacturing miniature hull fishing boat outrigger fiber glass so that partners fishermen groups can manufacture fishing boats outrigger made of fiber glass are actually independently as an attempt to divert outrigger fishing boats from wood to glass fiber materials for the development of the fishing fleet in order to maintain/increase the fish catch in order to improve the standard of living to a better direction. The method used in the manufacture of miniature outrigger fishing boat fiber glass in the form of a lecture following the discussion/question and answer and applicative training with the involvement of partner group of fishermen. Plan activities that will be done in the implementation of manufacturing miniature hull fishing boat outrigger fiber glass that provides counseling by introducing wood and fiber glass as well as equipment to be used for the manufacture of hull miniature fishing boats outrigger fiber glass, the composition of the fiber glass to see the standardization of the mixture and training manufacture of molded semi parmanen which continued with casting hull miniature outrigger fishing boats.
\end{abstract}

Keywords : Moulded, hull, miniature, outrigger canoe

\section{PENDAHULUAN}

\section{Latar Belakang}

Labuan dikenal dengan sebutan kota Nelayan

Karena letaknya di pesisir pantai selat sunda berada diketinggian 3 meter di atas permukaan laut, Selain wisata pantai, Labuan juga dikenal dengan kegiatan perikanannya. Labuan ditetapkan sebagai sentra perikanan laut di pesisir barat Banten. Kehidupan masyarakat di desa Caringin Kecamatan Labuan Kabupaten Pandeglang Propinsi Banten memiliki ikatan sosial yang tinggi, yang dapat diamati dari hubungan kekerabatan, struktur, organisasi masyarakat dan pola pemukiman tradisional yang masih terjaga. Tetapi tingkat pendidikan masyarakat di desa ini sangat rendah dan sebagian besar bermata pencaharian sebagai nelayan dan buruh nelayan. Kondisi ini berdampak terhadap tingkat pendapatan dan ke sejahteraannya yang rendah. Untuk memenuhi kebutuhan hidup sehari-hari, para nelayan dengan menggunakan perahu ikan cadik berbahan kayu melaut sejak pentang dan kembali keesokan hari dipagi hari, dimana hasil pencarian ikan sebagian dijual ke pasaran dan sebagian untuk dikonsumsi sehingga rata-rata masyarakat kelompok nelayan di kedua desa ini tidak terjangkau untuk memenuhi kebutuhan primer.

Provinsi Banten memiliki 78 pulau (termasuk Kepulauan. Seribu di Kabupaten Tangerang), diperkirakan 1/3 bagian wilayahnya terdiri dari lautan dengan luas perairan Propinsi Banten sekitar 11.134,224 km2 dengan panjang garis pantai 517,42 km (kompasiana.com). Kecamatan Labuan berjarak sekitar $41 \mathrm{Km}$ dari Pusat Kota Pandeglang, dengan luas wilayah 15,66 km2. Hasil produksi penangkapan ikan oleh masyarakat kelompok nelayan di Desa Caringin dapat dikatakan belum maksimal jika dibandingkan dengan luas perairan dan panjang garis pantai yang ada.

Kegiatan pengabdian bagi masyarakat dalam hal ini sebagai upaya mendukung kebijakan pemerintah untuk memberdayakan kelompok nelayan di desa-desa terpencil. Dalam hal ini akan dilakukan pelatihan dan pembuatan hull perahu ikan cadik berbahan fiber glass skala kecil bagi kelompok nelayan Desa Caringin Kecamatan Labuan Kabupaten Pandeglang Propinsi Banten, sehingga diharapkan mitra kelompok nelayan dapat memproduksi perahu ikan cadik fiber glass yang sesungguhnya.

\section{Analisis Situasi}

Sesuai analisis situasi bahwa perahu ikan cadik yang digunakan oleh para nelayan yang berjumlah \pm 50 orang untuk mencari ikan umumnya berbahan kayu dengan kondisi fisik umur pakai rata rata $\pm 70 \%$, sebagaimana diperlihatkan pada gambar 1 . Mengingat bahan kayu yang digunakan untuk membuat perahu ikan cadik sangat rentan 
terjadinya ilegal logging yang berdampak terjadi pengrusakan hutan kayu, sehingga perlu dilakukan pengalihan perahu ikan cadik dari bahan kayu ke bahan fiber glass. karena bahan fiber glass mudah diperoleh dipasaran dengan harga yang terjangkau disamping tidak membutuhkan investasi yang besar dalam proses pembuatan.

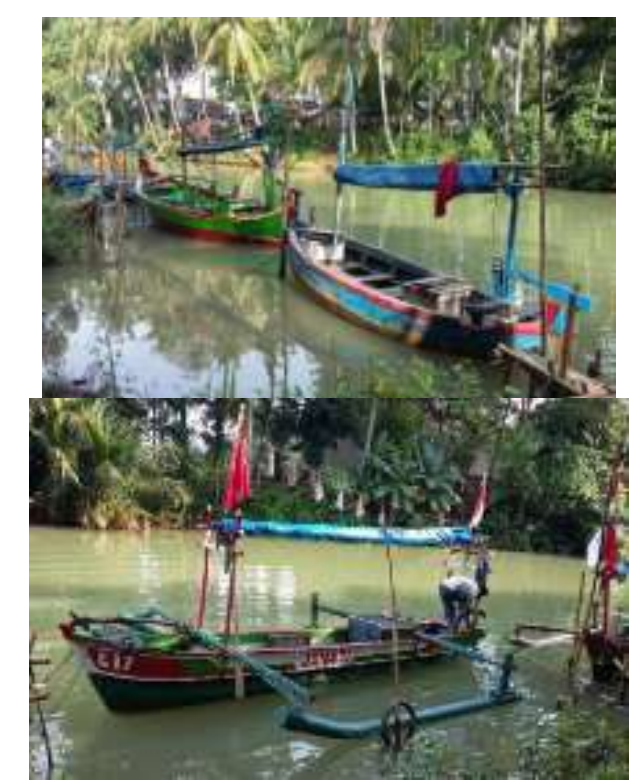

Gambar 1. Perahu ikan berbahan kayu yang dimiliki oleh mitra kelompok nelayan.

Penyuluhan berikut pelatihan dan pembuatan hull perahu ikan cadik fiber glass skala kecil kepada mitra kelompok nelayan desa Caringin Kecamatan Labuan Kabupaten Pandeglang Propinsi Banten sebagai upaya untuk pengembangan armada penangkapan ikan yang menggunakan bahan fiber untuk meningkatkan hasil tangkapan ikan demi meningkatkan taraf hidup masyarakat nelayan.

\section{TARGET DAN LUARAN}

Target dari kegiatan Pengabdian Kepada Masyarakat (IbM) agar mitra kelompok nelayan Desa Caringin Kecamatan Labuan

Kabupaten Pandeglang Propinsi Banten dapat membuat/memproduksi perahu ikan cadik fiber glass secara mandiri.

Luaran kegiatan Pengabdian Kepada Masyarakat kelompok nelayan Desa Caringin Kecamatan Labuan Kabupaten Pandeglang Propinsi Banten berupa produk hull perahu ikan cadik fiber glass sakala kecil berukuran Panjang 1 meter, Lebar 0,3 meter dan Tinggi 0,25 meter.

\section{METODE PELAKSANAAN}

Aspek Kehidupan Masyarakat Desa Caringin

Kehidupan masyarakat di desa Caringin Kecamatan Labuan Kabupaten Pandeglang Propinsi Banten sebagian besar bermata pencaharian sebagai nelayan. Kondisi ini berdampak terhadap tingkat pendapatan dan kesejahteraannya yang rendah.

Untuk memenuhi kebutuhan hidup sehari-hari, para nelayan dengan menggunakan perahu ikan cadik berbahan kayu serta kombinasi kayu dan plastik melaut sejak pentang dan kembali keesokan hari dipagi hari. Hasil pencarian ikan sebagian dijual ke pasaran untuk memenuhi kebutuhan hidup seharihari dan sebagian untuk dikonsumsi sehingga ratarata masyarakat kelompok nelayan tidak terjangkau untuk memenuhi kebutuhan primer.

\section{Justifikasi Dengan Mitra}

Kegiatan Pengabdian Kepada Masyarakat berupa penyuluhan berikut pelatihan dan pembuatan hull perahu ikan cadik fiber glass skala kecil telah disepakati oleh mitra kelompok nelayan Desa Caringin Kecamatan Labuan Kabupaten Pandeglang Provinsi Banten untuk pengembangan armada perikanan guna meningkatkan hasil tangkapan ikan demi meningkatkan taraf hidup masyarakat nelayan.

\section{Metode Pendekatan untuk Menyelesai- kan \\ Permasalahan}

Sebagai langkah untuk pengalihan perahu ikan cadik dari bahan kayu atau bahan plastik ke bahan fiber glass, diterapkan metode pelatihan dan pembuatan miniatur hull perahu ikan cadik fiber glass secara aplikatif dengan melibatkan mitra kelompok nelayan secara langsung dalam proses pembuatan agar dapat memproduksi perahu ikan cadik fiber glass untuk pengembangan armada perikanan.

\section{Tahapan Pelaksanaan Kegiatan}

Tahapan pelaksanaan kegiatan pembuatan miniatur hull perahu ikan cadik fiber glass meliputi antara lain:

a. Melakukan koordinasi dengan Camat Labuan Kabupaten Pandeglang Provinsi Banten dalam hal menyampaikan program kegiatan pengabdian bagi masyarakat di Desa Caringin berupa pelatihan dan pembuatan miniatur perahu ikan cadik fiber glass bagi kelompok nelayan, dilanjut dengan melakukan survei lapangan.

b. Menyiapkan materi pelatihan berkaitan dengan pembuatan hull perahu ikan cadik fiber glass skala kecil, yang meliputi:

1). Desain gambar rencana garis perahu ikan cadik untuk diproyeksikan ke lantai kerja dengan skala 1:1 guna memperoleh ukuran frames yang aktual.

2). Bahan kayu, fiber glass dan peralatan yang akan digunakan untuk pembuatan unit moulded hull;

3). Komposisi bahan fiber glass.

c. Pembuatan unit moulded hull semi parmanen, dengan tahapan antara lain:

1). Penggambaran lines plan pada 
mouldloft;

2). Marking/cutting frames;

3). Fabrikasi/assembling frames dan hull; 4). Pembuatan pondasi/dudukan maoulded.

3.1. Partisipasi Mitra dalam

Pelaksanaan Program

Partisipasi mitra kelompok nelayan Desa Caringin Kecamatan Labuan Kabupaten Pandeglang Provinsi Banten dalam kegiatan pembutan hull perahu ikan cadik fiber glass skala kecil, yakni menyiapkan lokasi/hanggar untuk tempat kegiatan penyuluhan dan pelatihan serta peralatan bantu berupa ember, gayung, gergaji tangan, linggis dan pakaian kerja.

\section{REKAM JEJAK PENGABDIAN KEPADA MASYARAKAT}

\section{Kegiatan Pengabdian Masyarakat Tiga}

(3) Tahun Terakhir

Kegiatan Pengabdian Masyarakat yang telah dilakukan dalam tiga tahun terakhir berupa pelatihan dan pembuatan hull kapal ikan 30 GT tipe purse seine fiber glass skala kecil bagi mitra kelompok nelayan Desa Sumberjaya Kecamatan Sumur Kabupaten Pandeglang provinsi banten berukuran Panjang $=1,5 \mathrm{~m}$, Lebar $=0,3 \mathrm{~m}$ dan Tinggi $\mathrm{T}$

= 0,35 m (by. Amir Marasabessy dan tim),

Nopember 2015) sebagaimana yang diperlihatkan pada gambar 2, pembuatan perahu ikan cadik berbahan fiber glass bagi mitra kelompok nelayan Pelabuhan Karangantu Kecamatan Kasemen Kota Serang Provinsi Banten berukuran Panjang $=6,5 \mathrm{~m}$, Lebar $=0,65 \mathrm{~m}$ dan Tinggi $=0,70 \mathrm{~m}$ (by. Amir Marasabessy dan tim), Nopember 2016) sebagaimana yang diperlihatkan pada gambar 3.

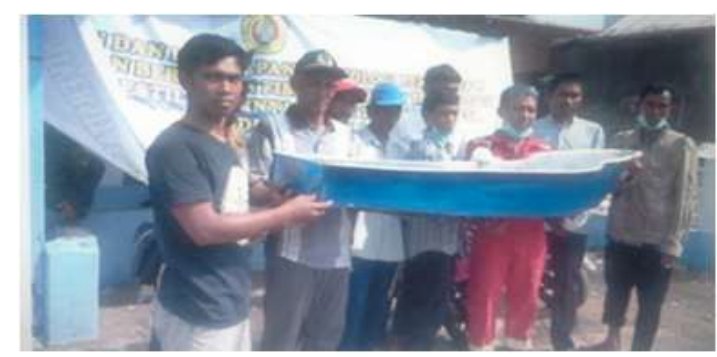

Gambar 2. Pelatihan dan pembuatan hull perahu ikan cadik fiber glass skala kecil bagi mitra kelompok nelayan di Desa Sumberjaya Kecamatan Sumur Kabupaten Pandeglang Provinsi Banten.

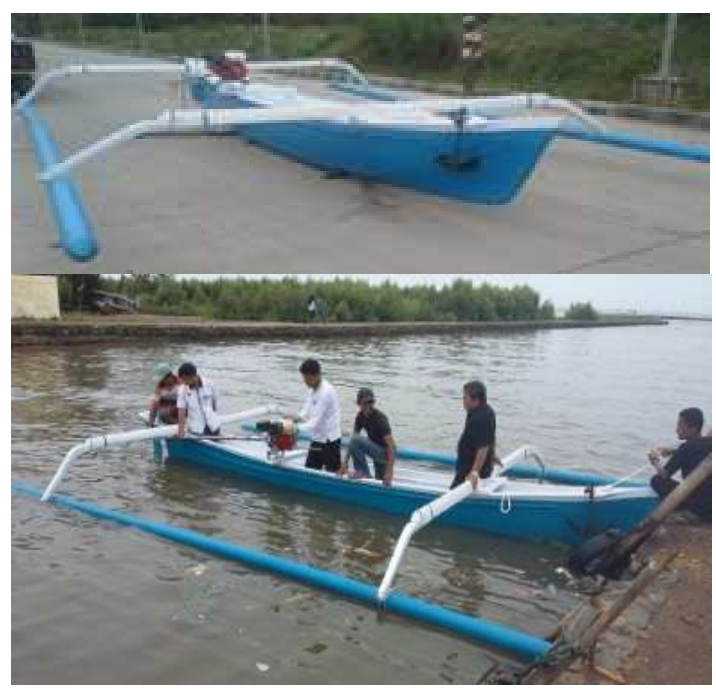

Gambar 3.Pelatihan dan pembuatan perahu ikan cadik fiber glass bagi mitra kelompok nelayan di Pelabuhan Karangantu Kecamatan Kasemen Kota Serang Provinsi Banten.

\section{Keterlibatan Pakar Dalam Pelaksanaan Program PKM}

Para pakar yang akan dilibatkankan dalam pelaksanaan program IbM pada kelompok nelayan Desa Caringin Kecamatan Labuan Kabupaten Pandeglang Provinsi Banten, antara lain:

a. Pakar dalam bidang produksi kapal, untuk memberikan pelatihan dan pembuatan moulded hull perahu ikan cadik parmanen skala kecil dan produknya;

b. Pakar dalam bidang material khususnya fiber glass untuk menjelaskan komposisi material;

c. Pakar dalam bidang desain engineering untuk merencanakan desain perahu ikan cadik fiber glass skala kecil.

\section{HASIL DAN LUARAN YANG DICAPAI}

\section{Hasil Kegiatan IbM}

a. Penyuluhan pembuatan moulded parmanen Penyuluhan pembuatan moulded hull perahu ikan cadik parmanen dengan bahan fiber glass diikuti mitra kelompok nelayan sebagaimana diperlihatkan pada gambar 4. yang berjumlah 19 orang.

b. Pelatihan pembuatan moulded hull parmanen Pelatihan pembuatan moulded hull perahu ikan cadik parmanen dengan bahan moulded dari fiber glass sebagaimana diperlihatkan pada gambar 5 


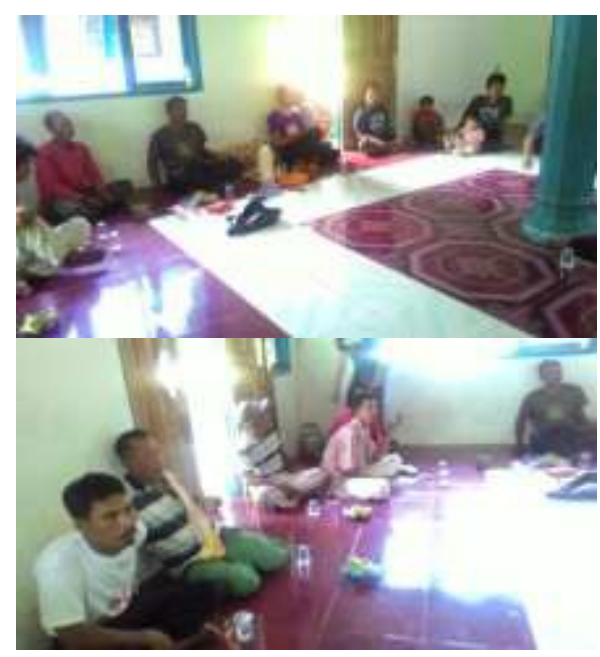

Gambar 4 Kehadiran mitra kelompok nelayan Desa Caringin Kecamatan Labuan Kabupaten Pandeglang Provinsi Banten dalam mengikuti penyuluhan pembuatan hull perahu ikan cadik fiber glass skala kecil.

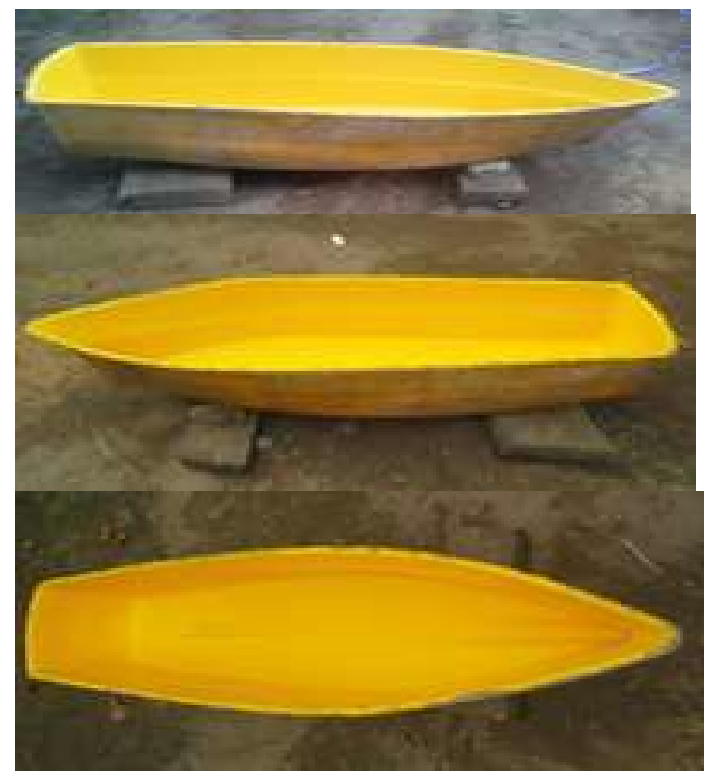

Gambar 5. Moulded parmanen hull perahu ikan cadik fiber glass skala kecil

c. Pelatihan pembuatan hull perahu ikan cadik fiber glass skala kecil Pelatihan pembuatan hull perahu ikan cadik fiber glass skala kecil dapat dijelaskan dengan tahapan sebagai berikut:

1). Persiapan bahan dan peralatan

Bahan dan peralatan yang dipersiapkan untuk pembuatan hull perahu cadik fiber glass skala kecil, antara lain:

- Bahan fiber glass sesuai gambar 6. berupa; mirror glaze, gelcoat, resin yukalac 157, Poly Vinyl Alcohol (PVA), katalis, CSM300, CSM450, WR600

- Peralatan kerja sesuai gambar 7. berupa; kuas roll baja, kuas roll bulu, kuas tangan, gelas ukur, gayung, ember, masker kain, sarung tangan kain, majun, mesin gurinda, pahat, gunting, palu dan cuter.

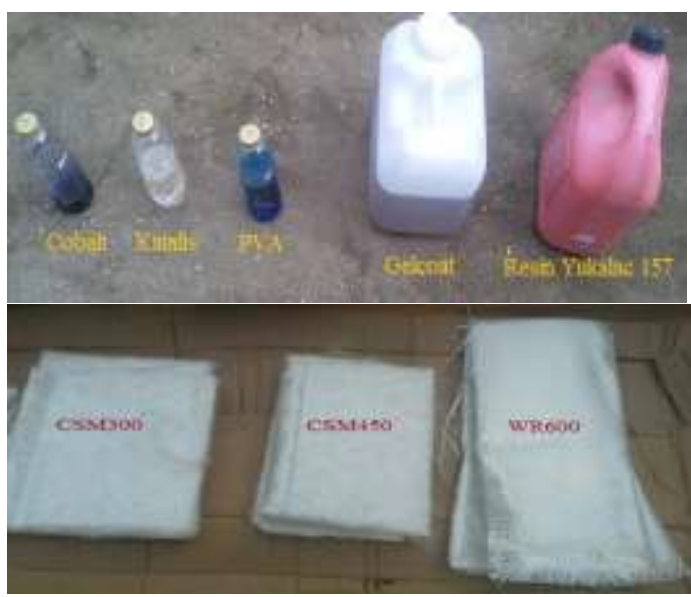

Gambar 6. Bahan fiber glass untuk membuat hull perahu ikan cadik skala kecil

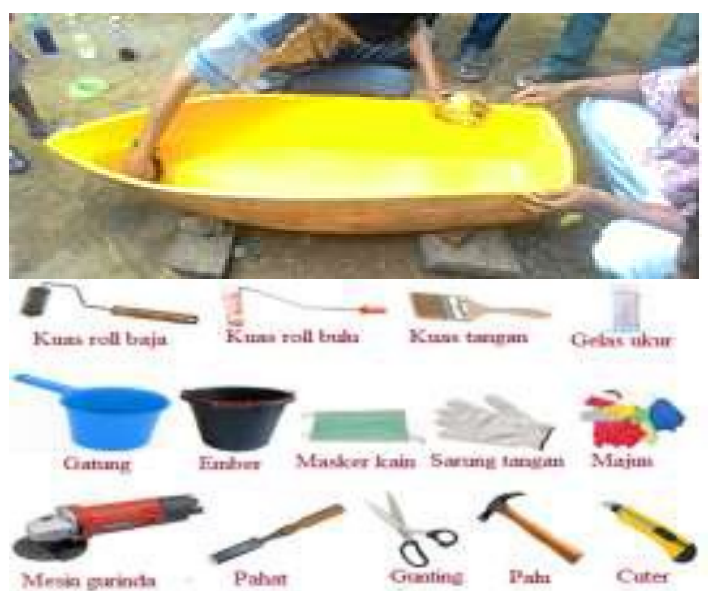

Gambar 7. Peralatan kerja untuk membuat hull perahu ikan cadik fiber glass skala kecil

2). Tahapan pembuatan miniatur hull perahu cadik

- Membersihkan moulded hull bagian dalam terhadap debu dan kotoran dengan menggunakan majun (gambar 8.);

- Pemolesan mirror glaze pada permukaan hull moulded bagian dalam sebanyak 5 s/d 6 kali pemolesan menggunakan majun (gambar 9.), hal ini dimaksud untuk mempermudah proses pencabutan produk hull dari moulded.

- Menunggu selang waktu 5 s/d 10 menit, pemolesan gelcoat sebagai lapisan pertama dan pewarna produk hull perahu ikan cadik sebanyak 2 s/d 3 kali menggunakan kuas tangan (gambar 10.), hal dimaksud untuk menyesuaikan ketebalan sesuai standarisasi. 


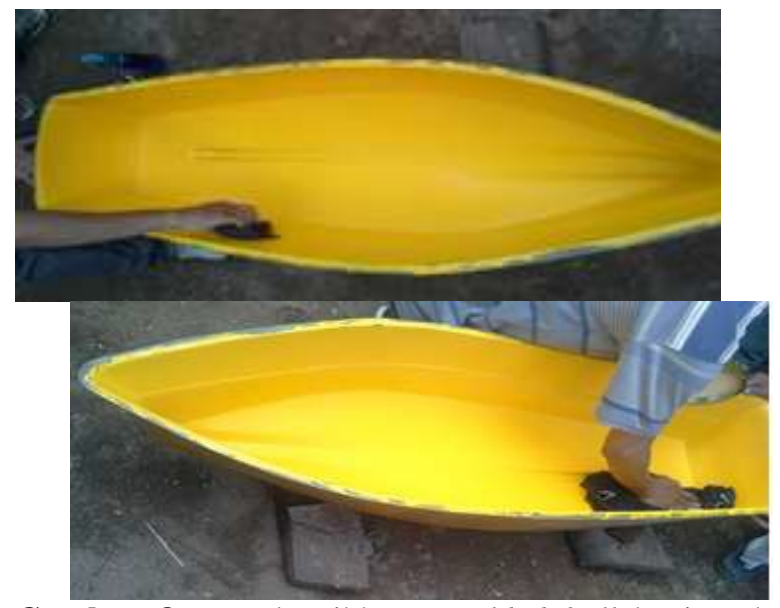

Gambar 8. Membersihkan moulded hull bagian dalam terhadap debu dan kotoran dengan menggunakan majun

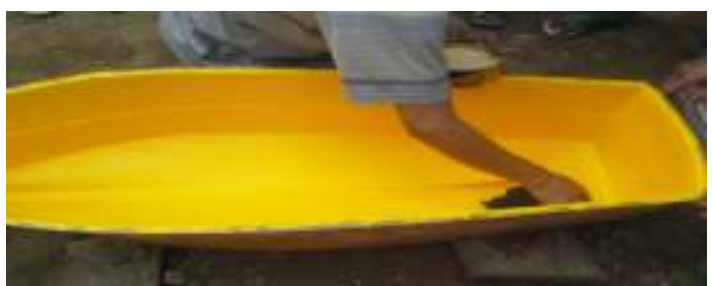

Gambar 9. Pemolesan mirror glaze pada permukaan moulded hull bagian dengan menggunakan majun

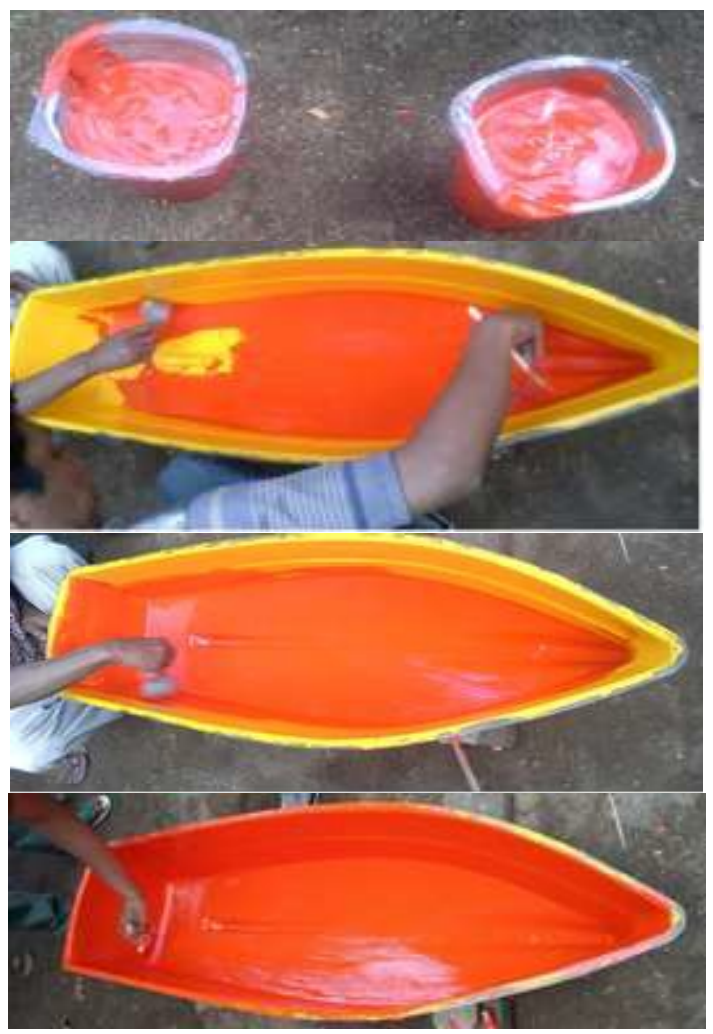

Gambar 10. Pemolesan gelcoat sebagai lapisan pertama dan pewarna produk hull perahu ikan cadik menggunakan kuas tangan

- Menunggu selang waktu 15 s/d 20 menit, laminasi CSM300 dilanjut laminasi CSM450 dan WR600 dengan media laminasi menggunakan resin yukalac 157 yang dicampur dengan katalis disesuaikan dengan komposisinya. Proses laminasi menggunakan kuas roll tangan dan kuas roll bulu kemudian penekanan laminasi menggunakan kuas roll baja hingga merata (sesuai gambar 11.) dan dipastikan tidak terdapat udara yang terperangkap (air trap) dalam serat penguat fiber glass.

- Menunggu selang waktu 30 s/d 45 menit dilakukan pencabutan produk hull perahu ikan cadik skala kecil dari moulded,

Sebagaimana yang diperlihatkan pada gambar 12.

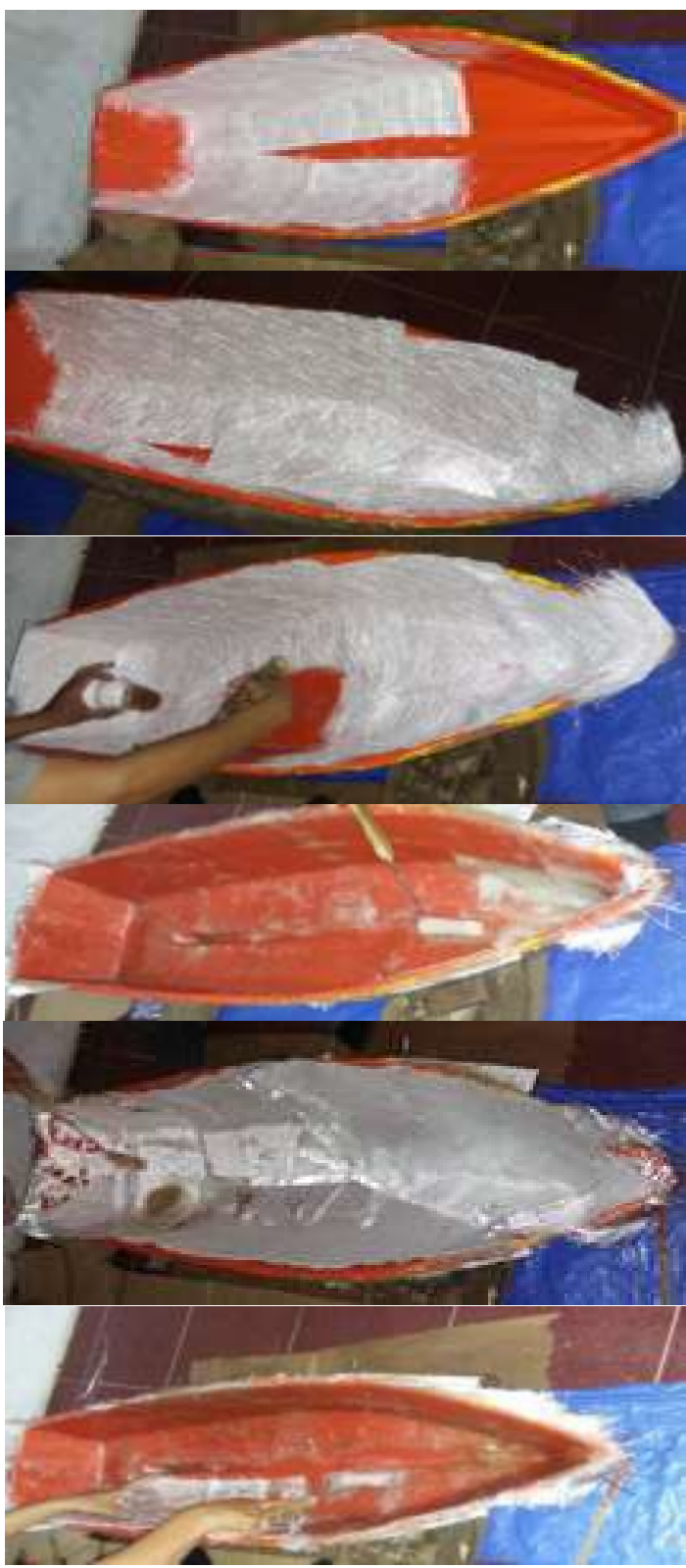

Gambar 11. Laminasi CSM300 dilanjut laminasi

CSM450 dan WR600 dengan media laminasi menggunakan resin yukalac 157 yang dicampur dengan katalis disesuaikan dengan komposisi. 


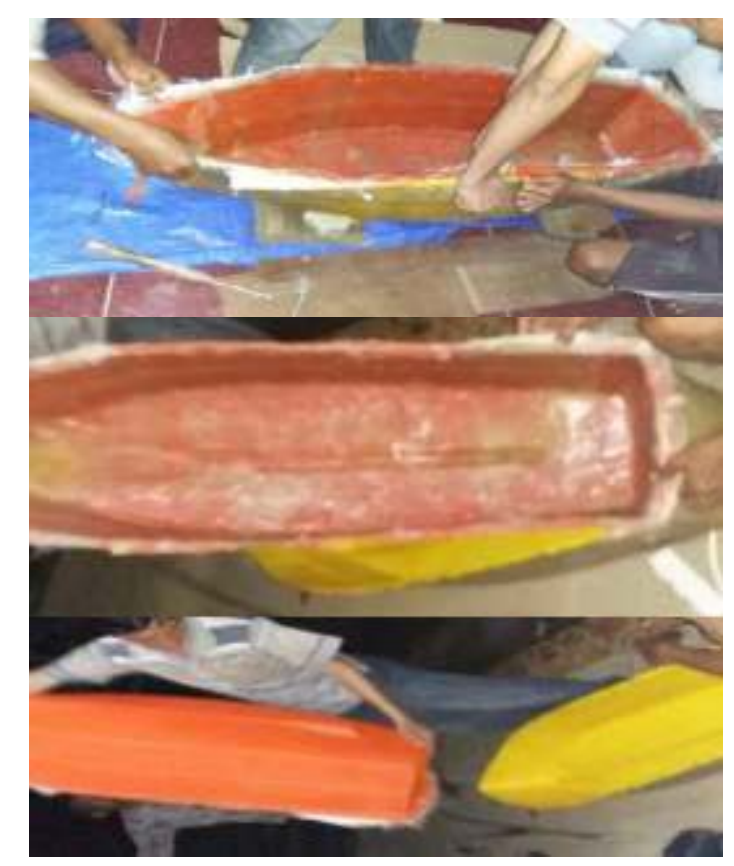

Gambar 12. Proses pencabutan produk hull perahu cadik skala kecil dari moulded

\section{Luaran yang Dicapai}

Adapun luaran yang dicapai dari hasil kegiatan Pengabdian Kepada Masyarakat (IbM) antara lain:

Mitra kelopmpok nelayan Desa Caringin

Kecamatan Labuan Kabupaten Pandeglang Provinsi Banten dapat mengerjakan produk hull perahu ikan cadik fiber glass skala kecil melalui kegiatan penyuluhan dan pelatihan dengan spesifikasi produk Panjang $(\mathrm{L})=1,00$ meter, lebar $(\mathrm{B})=0,30$ meter dan tinggi

(T) $=0,25$ meter sebagaimana yang diperlihatkan pada gambar 13 .

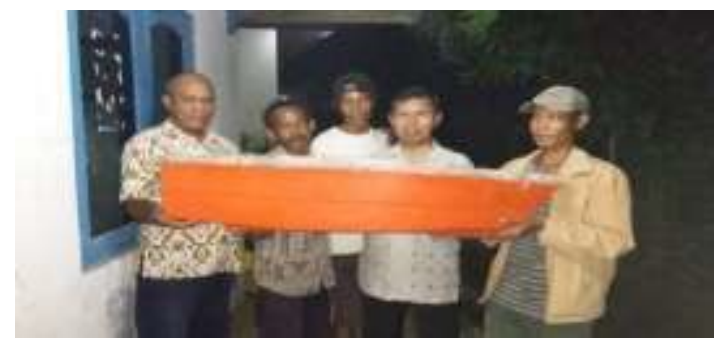

Gambar 13. Produk hull perahu cadik fiber glass skala kecil yang dikerjakan oleh mitra kelompok nelayan Desa Caringin Kecamatan Labuan Labuan Kabupaten Pandeglang Provinsi Banten

\section{RENCANA TAHAPAN BERIKUTNYA}

Rencana kegiatan Pengambdian Kepada Masyarakat (IbM) untuk tahap berikutnya yakni pelatihan dan pembuatan perahu ikan cadik fiber glass untuk mitra kelompok nelayan Desa Caringin Kecamatan Labuan Kabupaten Pandeglang Provinsi Banten dengan spesifikasi ukuran panjang $(\mathrm{P})=$ 6,50 meter, lebar $(\mathrm{B})=0,60$ meter dan tinggi $(\mathrm{T})=$ 0,65 meter, yang dilengkapi dengan mesin penggerak 5,5 Hp.

\section{SIMPULAN DAN SARAN}

\section{Simpulan}

- Kehidupan masyarakat Desa Caringin Kecamatan Labuan Kabupaten Pandeglang Provinsi Banten sebagaian besar sebagai nelayan, yang memiliki perahu ikan cadik berbahan kayu

- Masyarakat Desa Caringin Kecamatan Labuan Kabupaten Pandeglang Provinsi Banten menerima program kegiatan Pengabdian Kepada Masyarakat (IbM) pelatihan dan pembuatan hull perahu ikan cadik fiber glass skala kecil sebagai upaya pemberdayaan mitra kelompok nelayan untuk meningkatkan taraf hidup nelayan.

- Mitra kelompok nelayan Desa Caringin Kecamatan Labuan Kabupaten Pandeglang Provinsi Banten telah mempelajari bahan fiber glass dan peralatan kerja yang akan digunakan untuk membuat perahu ikan fiber glass serta telah mengetahui proses pembuatan hull perahu ikan cadik fiber glass skala kecil.

- Hull perahu ikan cadik fiber glass skala kecil yang dikerjakan mitra kelompok nelayan Desa Caringin Kecamatan Labuan Kabupaten Pandeglang Provinsi Banten dengan spesifikasi berukuran Panjang (L) = 1,00 meter, lebar (B) $=0,30$ meter dan tinggi $(\mathrm{T})=0,25$ meter

- Tahapan berikutnya dalam kegiatan (IbM) untuk mitra kelompok nelayan Desa Sumberjaya Kecamatan Sumur Kabupaten Pandeglang Provinsi Banten adalah pembuatan perahu ikan cadik fiber glass dengan spesifikasi ukuran panjang $(\mathrm{P})=6,50$ meter, $\operatorname{lebar}(\mathrm{B})=0,60$ meter dan tinggi $(\mathrm{T})=0,65$ meter, yang dilengkapi dengan mesin penggerak 5,5 Hp.

\section{Saran}

Selain kegiatan Pengabdian Kepada Masyarakat (PKM) yang telah dilakukan untuk memberdayakan mitra kelompok nelayan, diharapkan agar program Kuliah Kerja Nyata (KKN) dapat di lakukan, hal ini sesuai permintaan masyarakat Desa Caringin Kecamatan Labuan Kabupaten Pandeglang Provinsi Banten untuk dapat merubah pola pikir dan wawasan masyarakat guna meningkatkan taraf hidup ke arah yang lebih baik.

Berkaitan dengan bahan kayu untuk membuat perahu ikan cadik semakin sulit diperoleh dipasaran dan untuk menghindari terjadi ilegal loging maka perlu dilakukan perubahan dari bahan kayu ke fiber glass.

\section{DAFTAR PUSTAKA}

[1]. Buana Ma'ruf, Maret, 2011. A Study on Standardization of Fiberglass Ship's Hull Lamination Constructio.

[2]. Biro Klasifikasi Indonesia (BKI), Edisi 2006, Rules for Non Metallic 


\section{Materials Part 1.}

[3]. Amir Marasabessy, September 2015, Prosiding Seminar Nasional Akademi Maritim Nasional Cilacap, Pendidikan Maritim sebagai Pilar Poros Kemaritiman Indonesia.

[4]. S. Alameda St. Compton, Januari 2001, Fiberglass and Composite Material Design Guide.

[5]. U.S, September, 2008, Environmental Protection Agency Office of Air Quality Planning and Standards, Control Techniques Guidelines for Fiberglass Boat Manufacturing Materials. 